\title{
Predicting Failure to Pass Medical College Graduation Exam:
}

\section{Prediction of senior year medical students who do not pass the graduation exam by logistic analysis using data on gender, experience of repetition, and results of previous exams}

\author{
Type of article: Original \\ Kazuo Goto \\ Department of Clinical Laboratory Medicine, Teikyo University. \\ 2-11-1 Kaga, Itabashi, Tokyo 173-8605, Japan
}

\begin{abstract}
Background: The number of students who must repeat an academic year due to an inability to attain enough credits has been increasing in Japan. It is important for universities to be able to identify these students in advance to ensure that they pass their examinations without need of repetition. In this study, we tried to predict the likelihood of students' repetition of their senior year using the factors of gender, experience of repetition up to the junior year, and scores on tests conducted four times before their graduation exam in the senior year.

Methods: Seventy-three students belonging to the senior class of a medical technology college in Tokyo were studied. The students were divided into three groups: Group 1, composed of students who passed the graduation exam on the first attempt $(n=35)$; Group 2, composed of students who failed to pass the graduation exam at the first attempt, but passed the graduation re-exam $(n=26)$; and Group 3, composed of students who did not pass the graduation exam or the re-exam $(n=12)$.

Results: We found that gender was not a factor of senior-year repetition. Students who had experienced repetition prior to junior year tended to be six times more likely to fail the graduation exam than those who did not $(\mathrm{OR}=6.52,95 \% \mathrm{CI}: 1.17-32.44, P=0.03)$. Low scores on Test 4, administered two months before the graduation exam, were associated with students who fail to pass the graduation exam $(\mathrm{OR}=15.2,95 \% \mathrm{CI}: 3.29-70.14, P=0.00)$. The graduation exam score was associated with students who fail to pass the re-exam (OR=55.2, 95\% CI: $1.13-2679.86, P=0.04)$. Conclusion: This study suggests that we need to support senior-year students based on the results of pre-graduation testing, and we need to increase support for students with repetition experience before junior year.

Keywords: graduation exam, higher education, logistic analysis, repetition

Corresponding author: Kazuo GOTO email: gotok@med.teikyo-u.ac.jp Department of Clinical Laboratory Medicine, Teikyo University. 2-11-1 Kaga, Itabashi, Tokyo 173-8605, Japan tel +81-3-3964-1211 (ex44552) fax+81-3-5944-3354,eReceived: 13 April 2020. Accepted: 09 April, 2020. Published: 25 May, 2020.

Screened by iThenticate. (2017-2020 KNOWLEDGE KINGDOM PUBLISHING.
\end{abstract}

\section{Introduction}

The size of the 18-year-old population in Japan continues to decrease year after year, peaking at 2 million in 1992, then reaching 1.2 million in 2013. Meanwhile, the 18-year-old college enrollment rate has risen from 34.5 to $54.0 \%$, and has since stayed at around $55 \%$ [1].

With the popularization of universities, the "repetition rate" has been rising. The "repetition rate" refers to the rate of students who have to stay two years or longer in the same class due to being unable to attain enough credits. The repetition rate differs depending on departments of universities but on average, about $15 \%$ of 
students are unable to graduate within the minimum academic period, and this rate has been increasing [2,3, and 4].

There are several reasons for repetition, including physical reasons, spiritual reasons, environmental factors, active reasons, and passive reasons. Passive reasons are the most common reasons for repetition [5]; for example, repetition due to poor grades is included as a passive reason. If medical colleges or university health sciences programs are to prepare students to pass the national medical qualifications to be a medical doctor, nurse, radiologist, pharmacist, and medical technologist, it is important to educate students properly. Specifically, universities need to anticipate potential repetition students as they need more preparation to pass national exams without repetition.

In this study, we aimed to predict the students' repetition at fourth (senior) year, by analyzing gender, experience of repetition up to third (junior) year, and their scores on tests conducted in senior year before their graduation exam.

\section{Materials and methods}

\subsection{Target students}

This research was a retrospective study conducted from April 2019 to March 2020. A total of 73 students belonging to the senior class of a medical technology college in Tokyo were studied. The students were divided into three groups: Group 1, composed of students who passed the graduation exam at once $(n=35)$; Group 2, composed of students who failed to pass the graduation exam at the first attempt, but who passed the graduation re-exam $(n=26)$; and Group 3, composed of students who did not pass either the graduation exam or the re-exam $(n=12)$.

\subsection{Data collection and statistical analysis}

Factors such as gender, experience of repetition up to junior year, and scores on four tests (Tests 1 to 4) conducted in July, August, September, and October, respectively, were used in data collection. The graduation exam was performed in December, and the re-exam in the January after. The re-exam was conducted for those who failed the graduation exam. In Tests 1 to 4, a score of 60 or more out of 100 was regarded as passing. In the graduation exam and re-exam, a score of 125 or more out of 200 was regarded as passing. The data were analyzed statistically using the software SPSS for Windows (version 22). The Kolmogorov-Smirnov test was performed to determine whether continuous variables conformed to a normal distribution, and then the Student's t-test was used for the normally distributed data. Logistic regression analysis was used to detect the correlation between the repetition at senior year and the relevant factors. Odds ratios (ORs) are expressed with $95 \%$ confidence intervals $(\mathrm{CI})$, and a $\mathrm{P}$ value of less than 0.05 was considered statistically significant.

\section{Results}

\subsection{General characteristics}

Table 1 shows the characteristics of the 73 students, including the 37 students who passed the graduation exam and 36 students who failed to pass the exam. The 36 students were composed of the 24 students who passed the re-graduation exam and 
the 12 students who could not graduate because their re-graduation exam score was insufficient ( $<125$ scores). There was no gender difference among those who passed the graduation test, including the re-exam, and those who failed to pass the exams.

The students who experienced repetition up to junior year tended not to pass the graduation exam, compared with students who did not experience repetition $(\mathrm{P}<0.05)$. However, with regard to the results of the re-exam, no difference was found between the two in terms of the number of successful applicants.

The test scores on the four tests (Tests 1 to 4 ) and the graduation exam were higher in students who passed the graduation exam than students who failed to pass the exam $(\mathrm{P}<0.05)$, and the scores of students who passed the re-exam were higher than those of students who failed to pass the re-exam $(\mathrm{P}<0.05)$.

\subsection{Factors relating to students who fail to pass exams}

As shown in Table 3, logistic regression analysis confirmed that repetition experience up to junior year $(\mathrm{OR}=6.15,95 \% \mathrm{CI}$ : $1.17-32.44, \mathrm{P}=0.03)$, and scores on Test 4 were associated with students who failed to pass the graduation exam $(\mathrm{OR}=15.2,95 \% \mathrm{CI}: 3.29-70.14, \mathrm{P}=0.00)$. Additionally, the score of the graduation exam was associated with students who failed to pass the re-exam $(\mathrm{OR}=55.2,95 \%$ CI: $1.13-2679.86, \mathrm{P}=0.04)$.

\section{Discussion}

In Japan, the rate of enrolling in university among the 18-year-old population has been around $50 \%$ since 2005 [6], and about $15 \%$ of those students cannot graduate from a university within the prescribed term [2]. In one case of a university for medical technologists $(n=93), 6.5 \%$ of the students repeated their senior year in 2019 (data not shown). The urgent issue for such universities is how to lower the repetition rate.

In this paper, we focused on gender, experience of repetition up to the junior year, and scores of the four tests conducted before graduation exam in the senior year. We examined whether it is possible to predict repetition from these factors. Prediction of the likelihood of repetition can help identify students in need of additional preparation.

A previous study suggested that the repetition rate tended to be higher in male students than in female students [7]. The reasons for the repetition of female students were positive, such as studying abroad, changes in course, or preparations for qualification exams, and those of male students' were passive such as poor grades, mental problems, or hobbies [7].

On the other hand, there were no gender differences in this study. This is because both male and female students enroll in the university with a clear will to qualify as a healthcare professional, particularly a medical technologist.

Students who have experienced repetition up to junior year tend to fail to pass the graduation exam $(\mathrm{P}=0.05)$. There have been no studies focused on test scores among students who have experienced repetition. However, a previous study showed that the repetition rate of students who have experienced failing entrance exams of universities was higher than that of students who have no experience in 
failing entrance exams of universities [8]. Most of the target students in this study were those who had no experience in failing university entrance exams. It is necessary to focus more on students who have experienced repetition.

Four tests are administered to senior year students before the graduation exam. Focusing on these test scores, we examined whether a repetition forecast could be made. The score of students on Test 4 performed in October was the one mostly related to graduation exam result $(\mathrm{P}=0.04)$. The other three test scores were not. For the graduation re-exam, none of these scores were related to that of the re-exam, but the score of the graduation exam was related to that of the re-exam $(\mathrm{P}=0.04)$.

\section{Conclusion}

It is necessary to analyze different factors to predict repetition early so that students may be given necessary support. Individual subject grades up to junior year are not related to repetition at senior year (data not shown), but if overall grades up to junior year were poor, meaning that a student who has experienced repetition, the student is likely to repeat. This study suggests that we need to support senior year students based on the test results held at the end of October and students who have experienced repetition in their junior year.

\section{Declaration of conflicts}

There are no conflicts to declare.

\section{Author's Biography}

Dr Kazuo Goto: is a Professor at Teikyo University in Tokyo, Japan. He obtained his Doctor in Health Science (2000), and has contributed to teaching and research in the area of Laboratory Medicine, Medical Technology, and Laboratory animal Medicine. His research interest includes creation of human disease model animals using genetic modification, search of infectious disease of mouse and human, and education of medical technologists. He has served as a reviewer of international journals and conferences: as well as session chair at conferences.

\section{Reference}

[1] Ministry of Education, Culture, Sports, Science and Technology. Report \& Statistics. Enrollment and Advancement Rate: Enrollment and Advancement Rate. https://www.mext.go.jp/en/publication/statistics/title01/detail01/1373636.htm\#06 2020.

[2] Ogawa Y. A clinical study of repeaters. The annual report of the Kyoritsu college of pharmacy. 1976. 21:82-93. ISSN 04529731

[3] Matsubara T. The problem of repeaters in universities (I). 1979..Tsukubadaigaku shinrigaku kennkyu. 1:26-34. NII ID(NCID) AN0014895X

[4] Suehiro K. "Ryuunenn" on student of Today. 1983. Medical education. 14 (1) 4-8 ISSN-L 0386-9644 DOI https://doi.org/10.11307/mededjapan1970.14.4

[5] 5.Tateishi S and Ogata N. Dropping out from and repeating a grade in university and college. 2016. Koutoukyouikukennkyu 19:123-142. ISSN 1344-0063 DOI 10.32116/jaher.19.0_123 
Medical Technologies Journal, Volume: 4, Issue: 1, January-March 2020, Pages:497-503. Doi :

https://doi.org/10.26415/2572-004X-vol4iss1p497-503

[6] Goto K. Measuring academic achievement using selected exam subjects: The exam scores of medical technologist students. 2020. Medcal technologies journal, 4:455-470 Doi: https://doi.org/10.26415/2572-004X-vol3iss4p455-471455

[7] [Uchida C. Investigations on Leave, Dropouts, and International Students at Universities. 2011. Report of society of mental health 31:80-94]

[8] Fukuyama Y. "Ryunen" on a school year. Medical education 14:17-21. DOI: https://doi.org/10.11307/mededjapan1970.14.17

Table 1. Characteristics of the senior year-student population

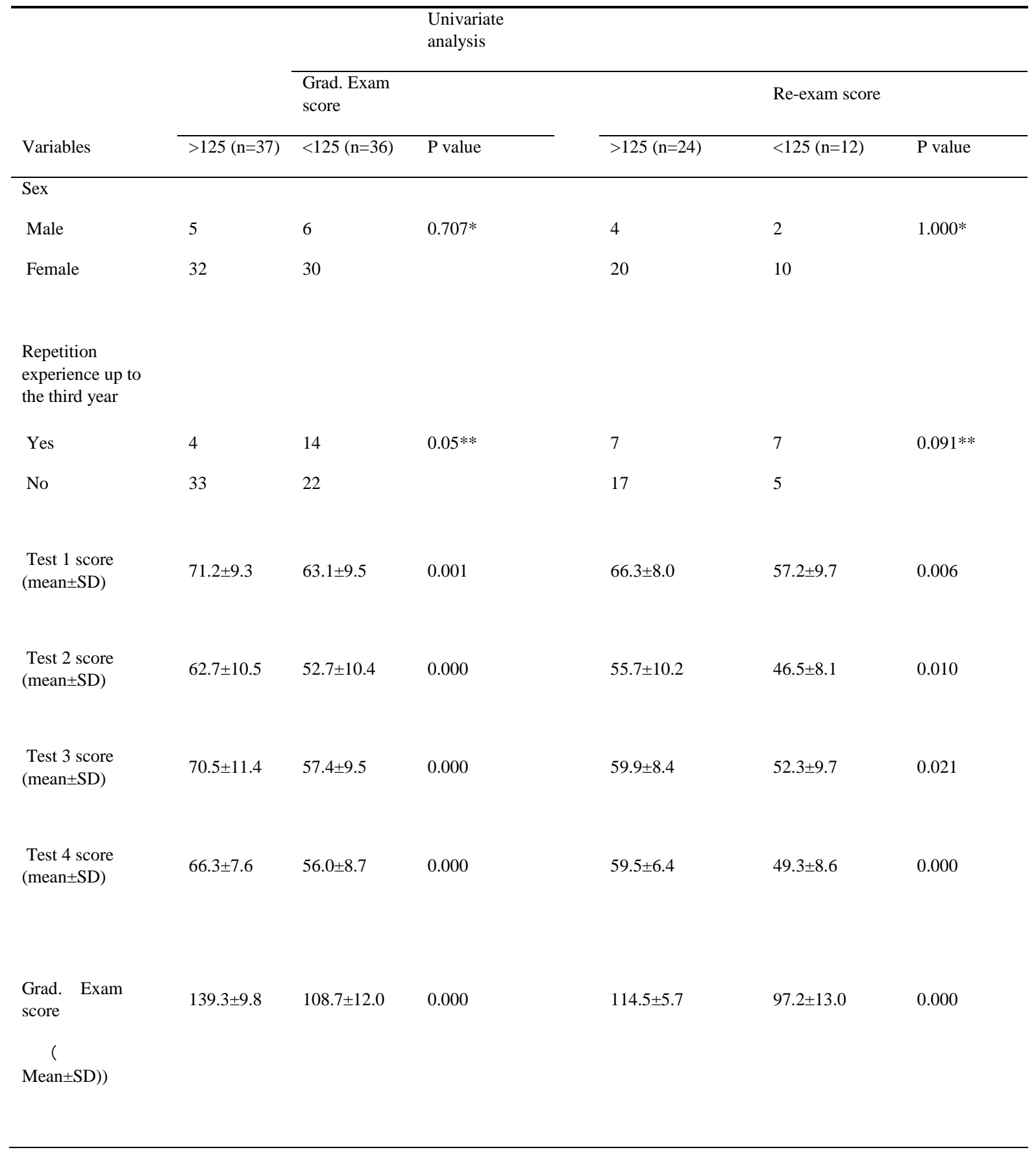


Medical Technologies Journal, Volume: 4, Issue: 1, January-March 2020, Pages:497-503. Doi : https://doi.org/10.26415/2572-004X-vol4iss1p497-503

Table 2. Multiple logistic regression analysis of variables associated with Students

who fail the first attempt of the graduation exam.

\begin{tabular}{|c|c|c|c|c|}
\hline Variables & & $\mathrm{OR}^{*}$ & $95 \% \mathrm{CI}^{* *}$ & $P$ value \\
\hline \multirow[t]{2}{*}{ Sex } & Female & Reference & & 0.24 \\
\hline & Male & 2.96 & $0.49-18.10$ & \\
\hline \multirow[t]{2}{*}{$\begin{array}{l}\text { Repetition experience up to the } \\
\text { third year }\end{array}$} & No & Reference & & 0.03 \\
\hline & Yes & 6.15 & $1.17-32.44$ & \\
\hline \multirow[t]{8}{*}{ Test scores } & Test $1>60$ & Reference & & 0.06 \\
\hline & Test $1<60$ & 6.52 & $0.93-45.75$ & \\
\hline & Test $2>60$ & Reference & & 0.81 \\
\hline & Test $2<60$ & 1.19 & $0.29-4.91$ & \\
\hline & Test $3>60$ & Reference & & 0.37 \\
\hline & Test $3<60$ & 2.15 & $0.40-11.51$ & \\
\hline & Test $4>60$ & Reference & & 0.00 \\
\hline & Test $4<60$ & 15.2 & $3.29-70.14$ & \\
\hline
\end{tabular}

*OR: Odds ratio

**CI: Confidence intervals 
Medical Technologies Journal, Volume: 4, Issue: 1, January-March 2020, Pages:497-503. Doi : https://doi.org/10.26415/2572-004X-vol4iss1p497-503

Table 3. Multiple logistic regression analysis: Variables associated with students who fail to pass 1 st graduation exam and the graduation "re-exam".

\begin{tabular}{|c|c|c|c|c|}
\hline Variables & & OR & $95 \% \mathrm{CI}$ & $\mathrm{P}$ value \\
\hline \multirow[t]{2}{*}{ Sex } & Female & Reference & & 0.79 \\
\hline & Male & 1.56 & $0.06-38.55$ & \\
\hline \multirow[t]{2}{*}{$\begin{array}{l}\text { Repetition experience } \\
\text { up to the third year }\end{array}$} & No & Reference & & 0.10 \\
\hline & Yes & 8.54 & $0.66-110.94$ & \\
\hline \multirow[t]{11}{*}{ Test scores } & Test $1>60$ & Reference & & 0.24 \\
\hline & Test $1<60$ & 4.93 & $0.35-70.13$ & \\
\hline & Test $2>60$ & Reference & & 0.65 \\
\hline & Test $2<60$ & 1.98 & $0.10-37.83$ & \\
\hline & Test $3>60$ & Reference & & 0.82 \\
\hline & Test $3<60$ & 1.34 & $0.10-18.15$ & \\
\hline & Test $4>60$ & Reference & & 0.08 \\
\hline & Test $4<60$ & 14.10 & $0.70-284.48$ & \\
\hline & $\begin{array}{l}\text { 1st Graduation } \\
\text { exam. }\end{array}$ & & & 0.04 \\
\hline & Score: $124-100$ & Reference & & \\
\hline & Scores: $<100$ & 55.22 & $1.13-2679.86$ & \\
\hline
\end{tabular}

